\title{
EL JURAMENTO REGIO. REFLEXIONES EN TORNO AL ARTÍCULO 61.1 CE
}

\author{
MIGUEL HERRERO DE MIÑÓN \\ Letrado Mayor del Consejo del Estado \\ Real Academia de Ciencias Morales y Políticas
}





\title{
EL JURAMENTO REGIO. REFLEXIONES EN TORNO AL ARTÍ́CULO 61.1 CE
}

\author{
POR \\ MIGUEL HERRERO DE MIÑÓN \\ Letrado Mayor del Consejo del Estado \\ Real Academia de Ciencias Morales y.Políticas

El juramento regio, previsto en el art. 61.1 CE, es una de las cuestiones constitucionales menos apreciada por la doctrina española. $Y$, sin embargo, analizado dentro de una interpretación sistemática de las normas constitucionales, arroja luz sobre cuestiones tan importantes como la sucesión a la Corona, las competencias regias y la misma naturaleza de lo que, parafraseando un título venerable, cabría denominar "La Monarquía según la Constitución".

Qué sea jurar es algo que ya ha dejado en claro una interpretación literal del precepto. Se trata de un compromiso personal que, si antaño se ponía bajo la sanción divina como garantía de su intensidad, hoy expresa el rango existencial de dicho compromiso'. Sin duda, en la actualidad el juramento se ha desvalorizado y relativizado en com-

1 En la doctrina española, López Guerra "Art. 61, Juramento" en Alzaga (ed.) Comentarios a la Constitución Española de 1978, Madrid (EDERSA) y ed., 1997, V, pág. 195 y ss. y SolozÁBAL, voz "Juramento", Enciclopedia Jurídica Básica, Madrid, 1995, Vol. 3, pág. 3857 y ss., además de las referencias en las obras generales; en la extranjera, de Lombardi "Giuramento" en Novissimo Digesto Italiano, Turín, 
paración con épocas anteriores. De ahí el ocaso del juramento decisorio como medio de prueba y en los sistemas jurídicos continentales más aún que en mundo jurídico anglosajón. La propia doctrina sentada por el Tribunal Constitucional en diferentes Sentencias (SS. 101/1983; 122/1983; 8/1985; 119/ 1990; 74/1991) revela este proceso de desvalorización mediante la formalización del juramento de los representantes para tomar posesión, tanto en cuanto hace a su exigibilidad, como a su contenido y a sus consecuencias.

En efecto, ante la cuestión de si puede o no condicionarse el acceso a la función de concejal o parlamentario a la prestación del juramento -o promesa - de acatamiento a la Constitución, el Tribunal se ha pronunciado reiteradamente en el sentido de que sólo mediante ley - lo que a estos efectos es lo mismo, el Reglamento de la Cámara, directamente incardinado en la Constitución, puede establecerse dicho requisito. Esto es remitiéndolo simplemente a la reserva genérica de ley para la regulación de los derechos fundamentales (SS. 101/1983, FJ 3, y 8/1985, FJ 4).

Respecto del contenido del juramento, la doctrina del Tribunal ha seguido una clara línea de relativización. Todavía en la S. 101/1983 se considera que implica "un deber general positivo de realizar sus funciones de acuerdo con la Constitución" que, en su virtud, los titulares de cargos públicos asumen en contraste con el deber general de los ciudadanos de abstenerse de su vulneración (FJ 3). Se trata, por lo tanto, de una versión de la distinción clásica entre la vinculación positiva y negativa con la ley de los poderes públicos y los administrados, lo cual supone reconocer en el juramento un compromiso substancial. Pero ya en la S. $122 / 1983$ el propio Tribunal reduce dicho compromiso a la aceptación "del juego político y el orden jurídico existente en tanto existe $y$ a no intentar su transformación por medios ilegales», de manera que la fidelidad a la Constitución no empece uperseguir ideales políticos diversos de los encarnados en la Constitución siempre que respeten aquellas reglas del juego" (FJ 5). Y la formalización llega a su extremo en la $S .119 / 1990$, reiterada por la $S .74 / 1991$, según las cuales la obligación de prestar juramento de acatamiento a la Constitución es un mero requisito formal, no para la adquisición de la condición de

1974, pág. 144 y ss.; y Friesenhann, Der politische Eid, Bonn, 1928 (ed. de 1979). Perspectivas historicistas en PRODI, I/ sacramento del potere. /I giuramento politico nella storia constituzionale dell/Occidente, Bolonia, 1992, y CALORE, "ll giuramento: un modelo storiografico?", en Materiafl per una storia della cultura giuridica, XXIII (1993), 2, pág. 509 y ss. 
representante que deriva del sufragio, sino para el ejercicio de las funciones propias de tal condición. Por lo tanto, dice el Tribunal, ula obligación de prestar juramento o promesa de acatar la Constitución no crea el deber de sujeción a ésta que resulta ya de lo que dispone el articulo. 9.1". Y si puede entenderse que refuerza este deber "creando un vínculo suplementario de índole religiosa o moral, esta vinculación más fuerte en el fuero interno no tiene, como tal, transcendencia juridica ni es, en consecuencia, la finalidad perseguida por la norma... que la impone" (FJ 4).

Por lo tanto, el juramento a la Constitución no supone más que la "carga", en el sentido técnico del término, para el acceso a una función. El tiempo y forma del cumplimiento de este requisito también se relativizan a tenor de la doctrina sentada en las dos últimas Sentencias citadas; pero su incumplimiento no supone sanción alguna, ni su prestación crea deber alguno, frente a lo que se decia en la inicial $\mathrm{S}$. $101 / 1983$.

Ciertamente, a la luz de tan autorizada doctrina, la exégesis del art. 61.1 CE ofrecería un interés relativo. Pero no es menos cierto que las Sentencias citadas del Tribunal.Constitucional se refieren al juramento de representantes parlamentarios y municipales $y$, en otros órdenes concretos, el juramento parece haber mantenido un sentido más substancial. Así en la función pública, el juramento exigido como requisito de perfeccionamiento por la Ley de 1964, vigente en este punto, ha sido relativizado por la doctrina y la jurisprudencia a simple requisito de eficacia $y$ aun de eficacia económica $y$, sin embargo, su significado podría ser el señalado en su día por la citada S. 101/1983. Como dice SolozÁBAL, el juramento de lealtad a la Constitución de funcionarios y jueces puede ofrecer una garantía suplementaria de atenerse a ella en su función de agentes ejecutores de la ley². De otra parte, en las Fuerzas Armadas el juramento sigue suponiendo un vínculo substancial a tenor del art. 20 de las Reales Ordenanzas de 1978, que explica otros muchos extremos del régimen militar. La categoría schmittiana del "orden concreto" en cuya vigente utilidad he insistido en otras ocasiones, sirve también para explicar las diversas versiones, ya más formalistas, ya más substancialistas de juramento.

Ahora bien, la Corona es, de suyo, un orden concreto; el que genera una institución. $Y$ en el juramento de fidelidad de su titular a la

2 . Loc. cit., pág. 3858. Todavía tiene vigencia GÁlVEZ, "El juramento de los funcionarios", en Documentación Administrativa n. 167 (1975) pág. 31 y ss. 
Constitución parecen concurrir notas substanciales que diferencian el juramento regio del de los concejales y lo asimilan más al de los soldados, por la radicalidad del compromiso moral que crea, por la sublimidad de las instituciones o valores a los que vincula, por la propia posición institucional de quien lo asume, por la sanción social que impetra, por su finalidad integradora. La diferencia es tan evidente que no es preciso insistir en ella.

Ahora bien, así concebido el juramento y juridificada su exigencia por el art. $61.1 \mathrm{CE}$, antes citado, ¿cuáles son los elementos de semejante institución?

\section{ELEMENTOS SUBJETIVOS}

El sujeto del juramento es sólo uno: el propio Rey, puesto que las Cortes tan sólo "lo reciben", como testigos que son de la proclamación en la que el juramento se integra. El Rey no es proclamado por las Cortes sino "ante" ellas, con fórmula que responde a nuestro derecho histórico y que se diferencia de otras conocidas por el derecho comparado ${ }^{3}$.

$Y$ es claro que el Rey no jura para serlo, sino por serlo. El ius ad officum del heredero de la Corona, se transforma en ius in officio por el solo hecho de la sucesión, como demuestra paladinamente el supuesto del Rey menor, sin que la proclamación ni el juramento sea una condición indispensable al efecto. Entre la muerte o abdicación de un Rey y la asunción de la Corona por su sucesor no hay interregno alguno, supuesto contemplado en otras constituciones monárquicas contemporáneas $y$ conscientemente excluido de la española vigente ${ }^{4}$.

En el caso del Monarca reinante, Don Juan Carlos I, el Rey, que era tal mucho antes de que hubiera Constitución, ni siquiera jura ésta, sino que la sanciona ante las Cortes y, después, la promulga. Se ha

$3 \quad$ V. gr. Bélgica (1831), art. 80, y Dinamarca (1953), art. 52.

$4 \quad$ V. gr. Bélgica (1831), arts. 79 y 80 . En España fue la interpretación dada al texto de 1812, Cf. LORENTE en Anuario de Historia del Derecho Español, LXV (1995), pág. 585 y ss. El ius ad officum y el ius in officio son tipicos derechos públicos subjetivos de función o funcionales (Romano "La teoria del diritti publici subjettivi» en Orlando, Trattato, Milán, 1987). Sobre la posición del heredero, Cfr... ToRRES DEL Moral, El Príncipe de Asturias. Su estatuto jurídico, Madrid, 1997. 
negado, con grande autoridad doctrinal ${ }^{5}$, pero contra el tenor expreso de los términos utilizados y de su interpretación auténtica por el propio Monarca ${ }^{6}$, que éste sancionara la Constitución, eliminando con ello un vínculo fundamental del Rey reinante y la norma fundamental, que excede de los principios generales del art. 9.1 CE.

En efecto, cualquiera que sea el significado actual de la sanción en la Monarquía parlamentaria e incluso en la propia Constitución española, ciertamente, en la culminación del proceso constituyente español, la sanción regia fue mucho más que una fórmula ritual.

Una visión mínimamente realista de dicho proceso constituyente no puede negar su condición de pacto ${ }^{7}$, de unión de voluntades, entre lo que LASSALLe denominó en su día "fragmentos de Constitución", uno de los cuales, sin duda, era la propia institución monárqui$\mathrm{ca}^{8}$. Negar esta realidad porque la Constitución fuera formalmente obra de las Cortes, representantes de "la Nación española en uso de su soberanía", es desconocer la coexistencia de actores y sujetos en todo proceso político, realidad política de la que el derecho debe hacerse eco para responder a la vida9. Si, como es bien sabido, la sanción suponía el asentimiento del Rey a la norma en la Monarquía limitada, a cuyo prototipo respondían las potestades regias anteriores a.la Constitución, incluso después de la Octava Ley Fundamental que fue la Ley para la Reforma Política de 1977, la sanción de la Constitución de 1978 no fue sino el compromiso del Rey con la nueva ordenación fundamental del Estado, con sus valores y procedimientos y, muy fundamentalmente, la conversión de su propia magistratura de órgano de soberanía y gobierno, en símbolo, moderador y árbitro. $Y$ este compromiso solemne equivale al juramento. Don Juan Carlos I, por ser Rey, aunque no juró, sancionó.

5 Aragón Reyes: Dos estudios sobre la Monarquia Parlamentaria en la Constitución Española, Madrid (Civitas), 1990, págs. 66-67).

6 Discurso de S.M. El Rey ante las Cortes el 27 de diciembre de 1978 «...al sancionar la Constitución y mandar a todos que la cumplan, expreso ante el pueblo español... mi decidida voluntad de acatarla y servirla" (DSC, pág. 6).

7 Cfr... mi estudio "La Constitución como pacto", Revista de Derecho Político (UNED), 44, 1998, pág. 15 y ss.

8 "Un Rey al que obedecen el Ejército y los cañones... es un fragmento de Constitución", (¿Qué es una Constitución?), trad. y edición de Eliseo AJA, Barcelona (Ariel), 1987, pág. 86.

9 Cf. GaRcí Pelayo, Las transformaciones del Estado contemporáneo, Madrid, 1977, pág. 108 y ss. 


\section{ELEMENTOS OBJETIVOS}

El objeto del juramento viene largamente enunciado en el texto constitucional, susceptible de un análisis tripartito.

En efecto, el Rey jura "desempeñar fielmente sus funciones", esto es, las que le atribuye el grupo de normas constitucionales y legales cuya cabecera es el art. 56.1 CE. Fidelidad supone un término de referencia de esa fidelidad que no es otro que la Constitución.

"Guardar y hacer guardar la Constitución y las leyes" es una habilitación, un límite y una meta. El Rey se compromete así a observar la Constitución, esto es, a no extralimitarse de las competencias que en la misma se le atribuyen y a no hacer, tampoco, dejación de las mismas. En lenguaje simple, al jurar observar la Constitución el Monarca parlamentario se compromete a no intentar gobernar - algo que corresponde al Gobierno, basado, a través de la confianza parlamentaria, en el principio democrático-, pero también y con el mismo rigor, a no dejar de reinar. Sólo ejerciendo las funciones propias del "reinar", por ejemplo a través, entre otras, de las competencias que le atribuye el artículo 62 CE., el Monarca puede "hacer guardar la Constitución".

Pero "hacer guardar la Constitución" es también una meta que ha de dar sentido al ejercicio de todas las competencias regias y en el servicio a esta meta consiste la fidelidad antes enunciada. Cuando el Rey represente $o$ arbitre o modere, de acuerdo con las cláusulas generales del artículo $56 \mathrm{CE}$, o cuando ejerce alguna de las competencias enunciadas en el artículo 62 , ha de hacerlo para que se cumplan los procedimientos previstos en la Constitución y se realicen los valores consagrados en la misma. El que lo haga bajo refrendo (arts. 56.3 y 64 CE) elimina su responsabilidad, pero no su deber.

De entre estos valores, es claro que el propio art. 61.1 destaca dos "los derechos de los ciudadanos y de las Comunidades Autónomas" que el Rey ha de respetar y hacer respetar en el ejercicio de sus funciones. Esto es, no deberá concurrir a conculcar tales derechos.

Afirmar que "guardar y hacer guardar" es una expresión meramente retórica porque el Rey carece de poder político para ello, es un ejemplo de mal razonamiento. La función regia, aunque careciera de todo poder, algo contrario a la literalidad y a la práctica de la Constitución, es evidente que puede ejercerse de acuerdo con ésta o, lo que trata de evitarse, contra su tenor y espíritu. $Y$ concluir que el art. 61.1 no tiene consecuencia alguna es ejemplo de la interpreta- 
ción que nulifica la norma porque no sabe o no quiera dar cuenta de ella.

En numerosos regímenes parlamentarios, tanto republicanos como monárquicos, se ha entendido $y$ entiende que un juramento de este tipo vincula al Jefe del Estado con la comunidad entera para actuar, en circunstancias normales y en supuesto de crisis, de tal manera que se mantenga o, en su caso, se restablezca la vigencia de los valores constitucionales $y$ las normas de funcionamiento de sus instituciones. Y lo que para ello es supuesto esencial, la existencia e independencia del Estado ${ }^{10}$. Por lo tanto, es lógico concluir que la inclusión del art. 61.1 en la Constitución de 1978 apunta a una opción semejante. ¿Qué otro significado podria tener? 0 , dicho en otras palabras, si la intención del constituyente español hubiera sido, por hipótesis, adoptar una fórmula en este punto semejante a la monárquica belga o la republicana alemana, ¿de qué otra forma más clara y contundente hubiera podido decirlo? A la hora de interpretar las normas constitucionales no está de más atender a su literalidad y contexto y no ser "adámico" - primordial inventor del nombre de las cosas-, sino dejarse llevar por la experiencia comparada para reconocer "la realidad social" en que las normas en cuestión han de ser aplicadas. El sentido común, aunque no siempre los prejuicios, coincide así con los criterios hermenéuticos del Código Civil.

¿En qué se concretan las consecuencias de este compromiso regio? Sin duda, ante todo, en el escrupuloso hacer que la Constitución exige - un Monarca parlamentario no es precisamente un Rey ocioso a la moda merovingia, o sueca o nipona, sino que, según el art. $56 \mathrm{CE}$, además de simbolizar, arbitra y modera- y abstenerse de lo que la Constitución atribuye a otros órganos -porque un Monarca parlamentario reina, pero no gobierna-.

La doctrina española $-y$ tal vez yo mismo haya contribuido inconscientemente a ello-, ha obscurecido la cuestion al hacerla girar en tomo a categoría tan brillante y polémica - una típica categoría con pico y garras- como la de defensa política de la Constitución. Asi formulada, la defensa política parece oponerse, como SCHMITT a KEISEN, a la defensa jurídica de la norma fundamental y suscita los fantasmas weimarianos de la dictadura constitucional.

10 Para las Monarquías, Vid. Moluor: La fonction rovale en Belgique, Bruselas, 1986, pág. 52, sobre el art. 80 , en relación con el 68 , de la Constitución. Respecto de Alemania, amplia bibliografía recogida en el apéndice a la ed. de 1979 de la obra de Friesenhann atrás citada. 
Ciertamente, la versión francesa de la dictadura constitucional al amparo del art. 16 se ha demostrado harto positiva a la hora de tutelar el orden constitucional-democrático. $Y$, en España, la tan criticada vinculación entre el compromiso regio de defender el orden constitucional y su Jefatura de las Fuerzas Armadas encargadas constitucionalmente de tal misión, demostró su plena eficacia práctica en $1981^{11}$.

Ahora bien, antes de llegar a tan extremos limites no debe olvidarse que el fiel ejercicio de las funciones regias y el guardar $y$ hacer guardar la Constitución y las leyes, se insertan, mucho más pacíficamente, en lo que STERN ${ }^{12}$ denomina la defensa procedimental de la Constitución que se confunde con el umoderar» (art. 56.1 CE). Esto es, en la instrumentación de la producción de actos de Estado mediante un procedimiento complejo en el que intervienen, controlándose recíprocamente, diferentes órganos uno de los cuales es, precisamente, el Jefe del Estado. La conexión de este instituto de garantía con el juramento supone algo tan lógico como conectar, en vez de oponer o substituir, las garantías jurídico-institucionales de la Constitución con las garantías políticas ${ }^{13}$.

Todos los actos del Rey son actos complejos, en cuanto sometidos al requisito de refrendo (art. $64 \mathrm{CE}$ ) y, además, muchos de ellos se insertan en actos-procedimiento en los que intervienen otros órganos distintos del Rey y del Gobierno. Por ejemplo, las Cortes (v. gr. art. 63.3), el Consejo General del Poder Judicial (v. gr. art. 123.2), el Tribunal Constitucional (v. gr. art. 160) o las Asambleas autonómicas (v gr. art. 151.1). La cuestión radica en saber si la intervención regia en tales actos es meramente mecánica y en consecuencia superflua o, de alguna manera, contribuye positivamente a la guarda de la Constitución, por introducir una instancia de control lo que, a su vez, requiere un margen de decisión.

La primera de estas posiciones se ha consolidado en la doctrina española merced a la categoría de "acto debido". De acuerdo con dicha tesis todos los actos del Rey en ejercicio de sus funciones son «debi-

1 Cfr... mi estudio "La actuación regia el 23 de febrero de 1981 " en Luis Jordana de Pozas, creador de ciencia administrativa, Madrid, 2000, pág. 93 y ss.

${ }_{12}$ Derecho del Estado de la República Federal Alemana (trad. esp.), Madrid, 1987, pág. 387 y ss. Sobre el moderar, contemplado en el art. $56.1 \mathrm{CE}$, cfr. mi estudio "Art. 56: El Rey" en Alzaga, Comentarios, cit., V. pág. 53 y ss.

13 Cfr... Jellinek, Teoría General del Estado (trad. esp.), Buenos Aires, 1973, pág. 473 y 592 y ss. 
dos", esto es, consecuencias forzosas de actos de terceros. En tal sentido, tanto la intervención regia en el acto refrendado como la del acto regio en el procedimiento, no supondrá ningún elemento de control sino una mera formalización cuya utilidad no cabe vislumbrar.

Una interpretación semejante es contraria al sentido literal de la Constitución - baste pensar en el "arbitra y modera... y ejerce las funciones" del art. $56 \mathrm{CE}$-, a su interpretación sistemática - al dejar sin contenido la propia fórmula del juramento del comentado art. 61 $\mathrm{CE}-$ y no responde en absoluto a la teoría ni a la práctica de la Monarquía parlamentaria, tanto británica como continental. Y ello a pesar de basarse sobre una exégesis de tal calificativo, "parlamentarian, donde el reinar sin gobernar supone algo más que las llamadas por BAGEHOT "partes ceremoniales» de la Constitución. Antes al contrario, como señalara en Bélgica el famoso Rapport sur... l'exercice des prérogatives $d u$ Roi, texto clave para conocer la práctica actual de la Monarquía parlamentaria, el Rey ha de actuar en el ejercicio de sus funciones "de tal manera que se consiga el fin para cuya consecución le fue atribuido dicho poder: asegurar el funcionamiento armonioso de las instituciones constitucionales" ${ }^{14}$. Sus potestades, como toda potestad en el Estado de Derecho, son funcionales, esto es, relativas a un fin.

Lo expuesto puede proyectarse en diferentes direcciones. Por ejemplo la interpretación del refrendo como acto complejo - del Rey $y$ del Gobierno refrendante según hiciera KEISEN — o como acto gubernamental solemnizado por el rey mediante un acto debido, cuestión que he tratado largamente en otro lugar al que ahora me remito ${ }^{15}$.

También y en inmediata relación con ello, a la hora de calibrar el llamado por la doctrina alemana "derecho de examen" por parte del Jefe del Estado de los actos en cuya producción ha de intervenir normalmente para culminarlos. No se trata de hacer del Rey un juez de la constitucionalidad de cada norma reglamentaria, cuya expedición proponga el Gobierno y, menos aún, de cada tratado o ley sometido a su sanción. Para eso están los tribunales ordinarios y el Constitucional, respectivamente. Pero es claro que resultaría absurdo forzar al Jefe del

14 Moniteur Belge, 6 de agosto de 1949, pág. 7594 y ss. Cf. Bogdanor, The Monarchy and the Constitution, Oxford, 1997, pág. 61 y ss.

${ }_{15}$ Cfr... "Art. 64: El Refrendo", en AlzaGA, ed., Comentarios, cit., V. pág. 279 y ss. Un replanteamiento último de la cuestión con síntesis de las diferentes tesis, en GonzÁlez TreviJano: El Refrendo, Madrid (CEC) 1998; mis matizaciones en el estudio citado en nota 11. 
Estado, al que la propia Constitución impone el juramento de guardarla y hacerla guardar, el deber de formalizar actos de Estado manifiestamente inconstitucionales, bien por no responder al procedimiento legalmente establecido para su producción o por violar manifiestamente el orden material de valores que la Constitución consagra. ¿Seria acaso lógico que el Rey designara un Presidente del Gobierno investido bajo presión armada o que sancionara una ley aprobada por una mayoría parlamentaria absoluta atentatoria a la libertad de expresión o que expidiese un Decreto de contenido manifiestamente ilegal? Una vez que en España se ha suprimido, felizmente, el eximente de obediencia debida cuando de delitos contra la Constitución se trata y cualquier funcionario judicial, civil o militar está obligado a no ejecutar actos contrarios a la Constitución, sería absurdo imponerle al Rey su formalización.

La doctrina alemana ha atribuido al Presidente Federal un derecho de examen de la constitucionalidad y legalidad formal y material que la prudencia aconseja detener en lo manifiesto y que la práctica ha demostrado muy amplio ${ }^{16}$. $Y$ otro tanto ocurre en las Monárquías parlamentarias europeas, con la excepción de Suecia. Dicho sea de paso, que en todos estos casos, tanto el Rey como el Presidente de la República están debidamente asistidos por servicios de Secretaria y Gabinete políticos. Sólo en España, pese a las posibilidades abiertas por el art. $65 \mathrm{CE}$, el Jefe del Estado parlamentario carece de estos instrumentos indispensables para el desempeño de su función ${ }^{17}$.

La garantía de la Constitución se plantea, pues, a través de esta "faculté d'empêcher" que está en el origen de la formulación moderna de la separación de poderes y de la propia configuración de la Jefatura del Estado como "pouvoir neutre", y que el oportuno estar informado, aconsejar y alentar, propio del moderar, prepara y, a la vez, evita. La doctrina se ha planteado reiteradamente la aporía de cómo puede el Jefe del Estado no atender las previsiones constitucionales - v. gr. expidiendo los Decretos acordados en Consejo de Ministros (art. 62.f)- - sin quebrantar la Constitución que pretende defender, al negar

16 Cfr... El testimonio de VON WEIZSÁCKER, Vier Zeiten. Eriderungen, Berlín (Siedler), 1997. Así, por ejemplo, el Presidente Federal, aun habiendo firmado el instrumento de ratificación del Tratado de Maastricht, no lo expidió hasta que el Tribunal Constitucional no dictó la S. de 12 de octubre de 1993. Doctrinalmente es interesante la evolución de STEIN entre la primera y segunda edición de su Derecho Político, un texto escolar típico (vid. trad. española, Madrid, 1973, pág. 96).

17 Cfr... Molitor: Op. cit., pág. 48 y ss. Para el modelo británico. Cf. BogdANOR: The Monarchy the Constitution, Oxford, 1997, pág. 197 y ss. 
su ineludible intervención a la hora de producir actos que estima manifiestamente contrarios al orden constitucional. A mi entender, en último extremo y la más solvente práctica comparada así lo avala, la voluntad regia, que nadie puede suplir ni coaccionar, debe actuar según las previsiones constitucionales, pero no ciegamente, sino teniendo como meta última el propio telos axiológico e institucional establecido por la Constitución. No será una voluntad personal, sino institucional; pero deberá ser una voluntad discrecional en su propio ámbito de decisión.

Pero el compromiso activo con la guarda de la Constitución, lo que los italianos llaman la cura o tutela institucional, puede ir más allá. Si las instituciones quiebran o se ven imposibilitadas para actuar libremente en el ejercicio de sus competencias, al Rey corresponde una función de suplencia dirigida al restablecimiento de la normalidad ${ }^{18}$. Así ocurrió en Bélgica en 1914, en Luxemburgo, Holanda y Noruega en 1940 y en España en 1981, y son numerosas las construcciones doctrinales formuladas al efecto. A $\mathrm{m}$ entender, lo que constitucionalmente explica esta suplencia no es una mera situación de hecho, sino las cláusúlas generales del art. 56, y lo que obliga al Rey a utilizarlas en el sentido indicado es el compromiso que expresó su sanción el 27 de diciembre de 1978 y, para el futuro, instrumenta el juramento regio previsto en el art. $61.1 \mathrm{CE}^{19}$.

Los requisitos de la actividad, forma, tiempo y lugar del juramento regio, han sido suficientemente esclarecidos por la doctrina y a ella me remito.

La forma es, sin alternativa de promesa, el juramento. $Y$ la transformación del significado de éste hace artificioso poner en colisión la fórmula del art. 61.1 con la libertad de conciencia del art. 16. Antes bien, la secularidad tradicional de la Monarquía española - que desde la Baja Edad Media prescinde de la consagración regia-, sólo alterada, merced a la influencia francesa, por nuestro constitucionalismo histórico a partir de 1812, y la toma en consideración del hecho religioso pre-

18 López Guerra, loc. cit. pág. 210.

19 Cfr... mi estudio "Art. 56. El Rey", en Alzaga (ed.), Comentarios cit., V. pág. 67 y ss. 
vista en el propio art. 16.2 CE, justifica sobradamente el mantenimiento del juramento.

En cuanto al tiempo y el lugar, el juramento tiene lugar al ser proclamado "ante las Cortes" el nuevo Rey.

\section{V}

Mayores problemas presenta la eficacia de las previsiones del citado art. 61.1 CE.

Es claro que el nuevo Rey está obligado por la Constitución al juramento, pero el incumplimiento de este deber carece de todo tipo de sanción. La inmunidad del Rey hace imposible construir una figura delictiva contra la Constitución como es el caso en la República Federal de Alemania (art. $61 \mathrm{GG}$ ). Y el juramento, como la proclamación, no es una condición para la sucesión de la Corona ni para el ejercicio de sus funciones. En España, frente a lo que ocurre en Bélgica o Dinamarca, el Príncipe heredero tiene un ius ad officum; pero, una vez convertido en Rey, tiene un ius in officio que no mediatiza un acto formal. No existe en el texto constitucional ni en sus antecedentes una sola referencia que permita concluir lo contrario. $Y$ propugnarlo citando, precisamente, el ejemplo belga como término de analogía, es contradecir la realidad.

En consecuencia, el deber que impone el art. 61.1 CE tiene un carácter de "natural», es decir, de vinculación no exigible y que alcanza relieve allí donde lo jurídico se abre a la ética y la política.

De todo lo expuesto cabe extraer ciertas consideraciones finales.

La primera, metodológica. La Constitución ha de ser interpretada de manera que todas sus disposiciones tengan sentido. No cabe nulificar unas con otras $-\gamma$ menos los substantivos mediante los adjetivos- sino que deben ser integradas para que las cabeceras de cada grupo normativo iluminen las normas integrantes del mismo y, a su vez, reciban de éstas contenido. La literalidad sólo adquiere pleno sentido en el contexto; pero, claro está, en un contexto literal, complementado por la doctrina del Tribunal Constitucional y, en su caso, la jurisprudencia y no suplido por los principios que el intérprete estime "políticamente correctos». La práctica comparada debe de ser tenida muy en cuenta, porque la Constitución de 1978 no es originaria y ni 
siquiera original, sino lo que Löwenstein denomina un texto derivado para cuya interpretación será bueno recurrir a las fuentes. Los antecedentes históricos y legislativos que invoca el art. $3 \mathrm{CC}$ son así las Constituciones italiana y alemana de 1948 y las Monárquías parlamentarias europeas, con exclusión del modelo sueco, que fue expresamente descartado por nuestros constituyentes.

La Monarquía parlamentaria (art. 1.3 CE) no es lo que el intérprete estima políticamente conveniente en función de criterios tan reactivos como relativos, al margen de los textos y la práctica universal de la institución. Es lo que los textos dicen a la luz de esta práctica.

La segunda, más de fondo, permite poner de manifiesto el carácter "existencial» de la Jefatura del Estado, tanto republicana como monárquica, como factor de integración política, más acentuado aún en el caso del Rey. El juramento regio pone de manifiesto su compromiso personal e institucional, ante la España que simboliza, en pro de unas instituciones y valores propios de una sociedad abierta. Si el juramento se encuentra desvalorizado en otros campos del derecho, su revalorización en este caso contribuye a lo que R. SMEND denominara integración constitucional, que si no se eleva al plano de lo existencial está condenada a disolverse en ritualismo procedimental vacio.

Que la Constitución sea no sólo revisable sino "abierta", como a una sociedad abierta corresponde, es la mejor respuesta a la hipertrofia existencialista que llevaba a Schmitt a decir: "Nadie jura fidelidad a un procedimiento de revisión", porque, precisamente, la posibilidad de revisión y aun de mutación es un valor clave de la Constitución abierta ${ }^{20}$.

Por último, lo dicho arroja nueva luz sobre la institución de la Monarquía. De una parte, si en el texto de 1978 sobran elementos para concluir que no se trata de una institución de nuevo cuño, sino que antecede en siglos la labor de los constituyentes (cfr. arts. 56.2 y 57.1 CE), la sanción de la Constitución, substitutiva del juramento, por Don Juan Carlos I en diciembre de 1978 , lo confirma aún más. El Rey no jura para serlo, sino porque lo es $y$, en su virtud no es proclamado por las Cortes, sino "ante ellas", lo cual ofrece más analogías con nuestro

20 Cfr... mi estudio "La dinámica de una Constitución abierta" en VV.AA.: 20 años después. La Constitución cara al siglo XXI, Madrid (Taurus), 1998, pág. 69 y ss., siguiendo las categorías de Häberle. 
constitucionalismo histórico y con el Estatuto albertino de 1848 o con las constituciones holandesa y noruega vigentes, que con la Constitución belga de 1831 o la danesa de 1953. Y esa evidencia no contradice en nada a la soberanía nacional proclamada en el art. 1.2 CE porque otro tanto ocurría en la Constitución de Cádiz. Y hoy está en la base de la noruega tanto como de la danesa.

La Corona se inserta en la Constitución que la configura aquí $y$ ahora, pero, si cronológicamente la antecede, hasta haberla hecho posible, lógicamente la excede.

De otro lado, el Trono no puede ser un sillón vacío si ha de servir al telos constitucional. No conviene a su funcionalidad exaltarlo tanto que se pierda entre las nubes. $Y$ asumir el contenido y las consecuencias del art. 61.1 CE contribuye a enraizarlo en el suelo de la realidad, más comprometido y trabajoso, pero más sólido también. 